\title{
Treatment of epilepsy with clonazepam and its effect on other anticonvulsants
}

\author{
R. N. NANDA, ${ }^{2}$ R. H. JOHNSON, ${ }^{2}$ H. J. KEOGH, D. G. LAMBIE, AND \\ I. D. MELVILLE
}

From the Department of Neurology, University of Glasgow, Institute of Neurological Sciences, Southern General Hospital, Glasgow, Scotland

SUMMARY Clonazepam was added to the treatment of patients with poorly controlled epilepsy in a double-blind trial and an open trial. Considerable improvement occurred with patients with myoclonic jerks and tonic-clonic convulsions, and with photosensitive epilepsy. Patients with atypical petit mal and focal epilepsies also improved. Drowsiness was initially common but lasted only a short time. No evidence was found for an action of clonazepam on the metabolism of other drugs, but treatment with pherobarbitone lowered serum concentrations of clonazepam. We conclude that clonazepam is particularly valuable in epilepsy with associated myoclonus and in photosensitive epilepsy.

Clonazepam (Rivotril, Roche Products Ltd) is a benzodiazepine compound which appears valuable as an anticonvulsant (Lund, 1972; Browne and Penry, 1973). We have previously communicated the results of a double-blind cross-over trial of clonazepam in 30 patients whose epilepsy was poorly controlled (Nanda et al., 1976). The trial extended over a period of nine weeks and we now report the results during the following year of the treatment in those patients who benefited. In addition, we report the effect of clonazepam therapy in 36 patients in whom the drug was introduced in an open trial for up to 16 months.

A therapeutic range of serum concentrations of clonazepam has not yet been established, and we have, therefore, measured serum concentrations of clonazepam in patients on doses of 3-12 mg daily, and examined the relationship of serum concentrations to seizure frequency. We also examined the effects of clonazepam on serum concentrations of phenytoin, phenobarbitone, and primidone, and the effects of continuing therapy with the drugs upon serum concentrations of clonazepam.

\section{Patients}

Thirty patients, 22 male and eight female, aged 11-40 years (mean 26 years) were studied in the double-blind

\footnotetext{
' Address for correspondence and reprint requests: Dr R. N. Nanda. Department of Medicine. Clinical Medical School, Wellington Hospital, Wellington 2, New Zealand.

2 Present address as in ${ }^{1}$

Accepted 22 December 1976
}

trial. Fifteen patients had generalised epilepsy with myoclonic jerks and tonic-clonic seizures, four had atypical absences, and 11 had focal epilepsy with fronto-temporal seizure source(s). Twenty-five patients were receiving various combinations of phenytoin, phenobarbitone, and primidone, and five were not receiving any medication. Twenty were inpatients in a residential epileptic centre and ten were treated as outpatients.

The 36 patients in the open trial of clonazepam19 male and 17 female, aged 11-44 years (mean 27 years) -were treated as outpatients. Seven patients had myoclonic jerks and tonic-clonic seizures, six had tonic-clonic seizures, seven had photosensitive epilepsy, and 16 had focal epilepsy with frontotemporal seizure source(s). All patients were receiving various combinations of phenytoin, phenobarbitone, and primidone.

\section{Methods}

Before the trials all patients were assessed clinically and an electroencephalogram (EEG) assessment was carried out. Further EEGs were obtained at the end of each part of the double-blind trial and during the open trial. In both trials clonazepam was added to the existing anticonvulsant regime. In the double-blind trial the initial dose of clonazepam was $1 \mathrm{mg} /$ day, increasing every third day by $1 \mathrm{mg} /$ day until the daily dose was $3 \mathrm{mg} /$ day ( $1 \mathrm{mg}$ morning and $2 \mathrm{mg}$ at night). Matched placebo tablets were also used. At the end of four to six weeks the first tablets were reduced slowly while the second unknown tablet was introduced. In 
the open trial, the clonazepam dose was also increased to an initial dose of $3 \mathrm{mg}$ daily, and the dose later increased or decreased as required. Those patients who benefited during the double-blind trial were also managed in the same way. All outpatients recorded the frequency of their own seizures and any side effects on specially prepared charts. Inpatients kept similar records and, in addition, seizures and untoward effects were recorded by the nursing staff.

Blood samples were taken before and after clonazepam treatment for measurement of serum concentrations of anticonvulsants, and for haematological examination and estimations of liver function, blood urea, and electrolytes. Measurements of phenytoin, phenobarbitone, and primidone were performed by a gas chromatographic technique (Goudie and Burnett, 1973). Clonazepam was measured by a radioimmunoassay technique at the Psychoendocrine Centre, St James's Hospital, Dublin (by courtesy of Dr D. A. O'Kelly).

\section{Results}

\section{SEIZURE FREQUENCY}

The effect of clonazepam on seizure frequency for the patients in the double-blind trial, both during the trial and after one year, is shown in Table 1 . In the 15 patients who had frequent myoclonic jerks, 12 of whom also had tonic-clonic seizures, clonazepam caused suppression of myoclonic jerks in 12 patients, and reduction of $80 \%$ in frequency of jerks in the other three; tonic-clonic seizures ceased to occur in eight patients and were reduced by $50 \%$ in the other four. The effectiveness of clonazepam therapy in the patients who improved was the same after one year as during the trial, but in four cases the clonazepam dose was increased to maintain effectiveness, doses of up to $12 \mathrm{mg}$ daily (one patient) being given without side effects. It was possible to reduce or stop other anticonvulsants in four patients.
Four patients in the double-blind trial had atypical absences with tonic-clonic seizures. On clonazepam, three showed suppression of both absences and tonicclonic seizures while the fourth showed no reduction in seizure frequency. The results after one year were less satisfactory, with only two of the three patients still on the drug showing improved control of absences.

Eleven patients in the double-blind trial had focal attacks and tonic-clonic seizures. There was a $50 \%$ reduction in tonic-clonic seizures during the trial in only four patients, and after a year only two of these continued to show improvement. The overall changes in dosage of clonazepam in the patients who continued to take the drug after the double-blind trial are shown in Table 2.

Table 2 Changes in dosage of clonazepam after one year in the 22 patients who continued to take the drug after the double-blind trial. At the end of the year no patients complained of side effects

\begin{tabular}{lllll}
\hline & $\begin{array}{l}\text { Withdrawn } \\
\text { from therapy }\end{array}$ & $\begin{array}{l}\text { Clonazepam } \\
\text { (mg/day) }\end{array}$ & \\
\cline { 3 - 5 } & & 3 & $<6$ & $>6$ \\
\hline $\begin{array}{l}\text { Number of patients treated } \\
\begin{array}{l}\text { after trial } \\
\text { after one year }\end{array}\end{array}$ & $\mathrm{Nil}$ & 22 & & \\
\hline
\end{tabular}

For the patients in the open trial, the effect of clonazepam on seizure frequency after one year is shown in Table 3. Seven patients with myoclonic epilepsy and tonic-clonic seizures ceased to have attacks, and have remained free of attacks for a year. Of seven patients with photosensitive epilepsy, six showed abolition of seizures and the seventh marked improvement.

Clonazepam was less effective in the six patients

Table 1 Effect of treatment with clonazepam in 30 patients with epilepsy in the double-blind trial and after follow-up for one year. In eight patients who did not benefit during the trial clonazepam was withdrawn. 100\%: no further attacks

\begin{tabular}{|c|c|c|c|c|c|c|c|c|c|}
\hline \multirow[t]{3}{*}{ Type of epilepsy } & \multirow{3}{*}{$\begin{array}{l}\text { Number of } \\
\text { patients }\end{array}$} & \multicolumn{8}{|c|}{ Degree of improvement } \\
\hline & & \multicolumn{4}{|c|}{ Trial result } & \multicolumn{4}{|c|}{ After one year } \\
\hline & & $100 \%$ & $80 \%$ & $50 \%$ & $0-50 \%$ & $100 \%$ & $80 \%$ & $50 \%$ & $0-50 \%$ \\
\hline \multicolumn{10}{|l|}{$\begin{array}{l}\text { Myoclonic } \\
\text { jerks }\end{array}$} \\
\hline \multicolumn{10}{|l|}{ Jerks +tonic-clonic } \\
\hline jerks & 12 & 9 & 3 & & & $8^{*}$ & 3 & & \\
\hline tonic-clonic & 12 & 8 & & 4 & & 7 & & 4 & \\
\hline Atypical absences & 4 & 3 & & & 1 & & 2 & & 1 \\
\hline \multicolumn{10}{|l|}{ Fronto-temporal } \\
\hline focal & 7 & & & & 7 & & & & \\
\hline tonic-clonic & 4 & & & 4 & & & & 2 & 2 \\
\hline
\end{tabular}

* One died after six months-unrelated cause. 
Table 3 Response after one year of patients in open trial of clonazepam. $100 \%$ : no further attacks

\begin{tabular}{|c|c|c|c|c|c|c|}
\hline \multirow{2}{*}{$\begin{array}{l}\text { Type of } \\
\text { epilepsy }\end{array}$} & \multirow{2}{*}{$\begin{array}{l}\text { Number } \\
\text { of } \\
\text { patients }\end{array}$} & \multicolumn{5}{|c|}{ Degree of improvement } \\
\hline & & $100 \%$ & $80 \%$ & $50 \%$ & $0-50 \%$ & Worse \\
\hline $\begin{array}{l}\text { Myoclonic } \\
\text { jerks and } \\
\text { tonic-clonic }\end{array}$ & 7 & 7 & & & & \\
\hline Photosensitive & 7 & 6 & 1 & & & \\
\hline Tonic-clonic & 6 & 2 & & 2 & 1 & 1 \\
\hline Fronto-temporal & 16 & & & 9 & 5 & 2 \\
\hline
\end{tabular}

with only tonic-clonic seizures, and was stopped in two patients, in one case because of side effects of the drug and in the other due to increase in the number of attacks. Sixteen patients with fronto-temporal epilepsy were studied but at the end of the year only nine remained on the drug. Clonazepam was stopped in two patients because seizures increased and in five patients because they showed no improvement or had side effects.

\section{UNWANTED EFFECTS}

Forty-four of the 66 patients complained of drowsiness in the first week after clonazepam was given. In these patients drowsiness improved after the first week although the dose of the drug was being increased slowly. After two to three weeks only six of the patients (all in the open trial) continued to complain of drowsiness. These six patients were also ataxic, with hypotonicity of trunk and lower limb muscles. Clonazepam was reduced and then stopped in these patients. One patient in the open trial became depressed while on clonazepam, and the drug had to be withdrawn. In another patient, a 12 year old boy, a change of personality, with irritability and violent behaviour was reported, and the drug was withdrawn. One patient reported excessive hair loss in the first month after starting clonazepam. This effect was transient and the patient continued to take the drug. At the end of one year none of those continuing treatment (45 patients) complained of any side effects.

\section{ELECTROENCEPHALOGRAPHY}

Ten patients with myoclonic epilepsy showed generalised polyspike-wave seizure discharges, and this paroxysmal activity was not recorded in seven patients during clonazepam therapy. Two patients had progressive myoclonic epilepsy (Unverricht's syndrome) and showed theta rhythms and spike/wave activity in their EEGs; there was no change in their EEGs during clonazepam therapy. The other patients with myoclonic epilepsy showed no abnormalities. All patients with photosensitive epilepsy showed seizure EEG activity with photic stimulation. Clonazepam therapy suppressed this photosensitive response in all EEGs recorded during the trial at monthly intervals. In all other patients EEGs were unchanged on clonazepam.

\section{OBSERVATIONS ON BLOOD-ANTICONVULSANT \\ CONCENTRATIONS, HAEMATOLOGY, AND \\ BIOCHEMISTRY}

Serum concentrations of phenytoin, phenobarbitone, and primidone in the patients in the double-blind trial were not significantly altered by the addition of $3 \mathrm{mg}$ of clonazepam daily for four weeks (Fig. 1).

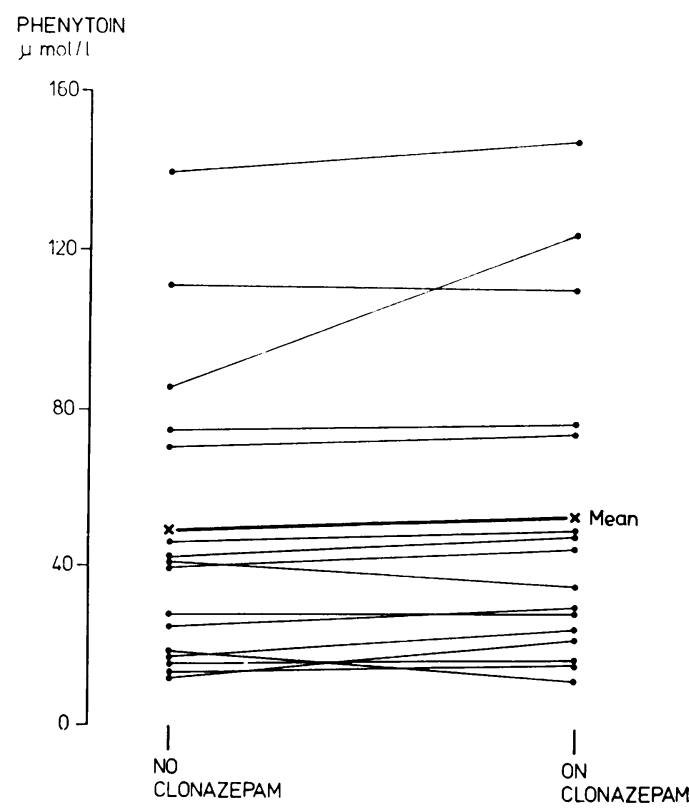

(a)

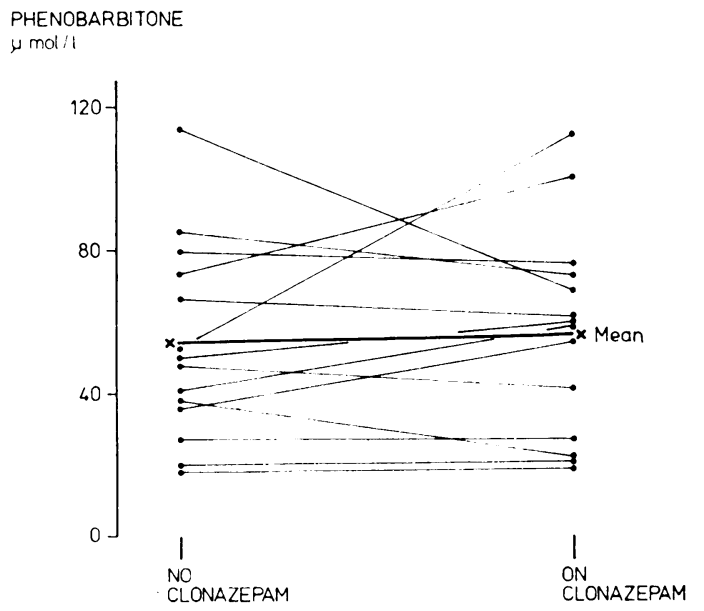

(b) 
PRIMIDONE

$\mu \mathrm{mol} / 1$

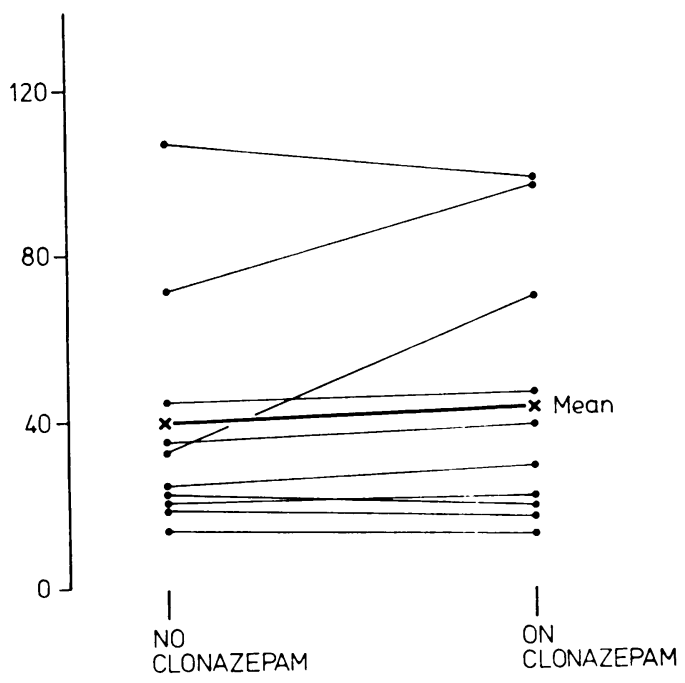

(c)

Fig. 1 (a) Plasma phenytoin $(n=16),(b)$ phenobarbitone $(n=14)$, and $(c)$ primidone $(n=10)$ before the doubleblind trial and at the end of the trial period in which clonazepam was added.

Serum concentrations of clonazepam in these patients ranged from 0.3 to $104 \mathrm{nmol} / \mathrm{l}$ (Fig. 2). In the open trial, plasma clonazepam concentrations in patients whose epilepsy was well controlled on $2-12 \mathrm{mg}$ of clonazepam daily ranged from 17 to $330 \mathrm{nmol} / 1$ (Fig. 3). Treatment with other anticonvulsants appeared to decrease serum concentrations of clonazepam. A graph of phenobarbitone concentrations against clonazepam concentrations has a negative slope with a significant negative correlation $(\mathbf{P}<0.01)$ (Fig. 4) suggesting that phenobarbitone depresses clonazepam concentrations in blood. No biochemical or haematological abnormalities were noted during treatment with clonazepam.

\section{Discussion}

The results of these trials indicate that clonazepam is very effective in the treatment of generalised epilepsy with myoclonic jerks alone or with tonic-clonic seizures. This result is of considerable importance as this form of epilepsy has previously been very difficult to treat (Van Woert and Sethy, 1975). The drug was also found to be particularly effective in photosensitive epilepsy. The value of the drug in epilepsy with associated myoclonus has been demonstrated in open trials but the numbers of patients have been small,
CLONAZEPAM

$n \mathrm{~mol} / \mathrm{I}$

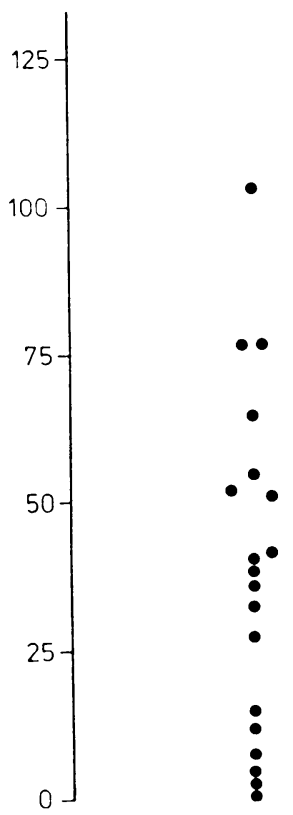

Fig. 2 Plasma clonazepam in patients in the doubleblind trial on $3 \mathrm{mg}$ of clonazepam daily $(n=19)$.

two trials only having five patients each with this condition (Goldberg and Dorman, 1976; Huang et al., 1974). In a double-blind trial, Edwards and Eadie (1973) have shown that the drug is of value as a wide spectrum anticonvulsant, but few of their patients had myoclonic epilepsy, and there is no indication that any had photosensitive epilepsy. Our results for patients with atypical absences, tonic-clonic epilepsy, and temporal lobe epilepsy also indicate that clonazepam is sometimes of value in these forms of epilepsy.

In focal epilepsy our results in the patients in the double-blind trial suggested that the drug was of little value. This is contrary to the experiences in other centres (Huang et al., 1973; Scollo-Lavizzari et al., 1974), and it is possible that the daily dosage of $3 \mathrm{mg}$ of clonazepam in our trial was insufficient for control of this type of epilepsy as a higher dosage was reported as being necessary in temporal lobe epilepsy (Huang et al., 1973). More satisfactory results were obtained in our open trial when the clonazepam dosage was increased (up to $10 \mathrm{mg}$ daily) in the focal epilepsies.

Serum concentrations of clonazepam in our patients ranged from $0.3-330 \mathrm{nmol} / 1$ on a daily dose of 2-12 mg. It has previously been reported (Naestoft et al., 1973; Dreifuss et al., 1975) that after daily oral doses of $1.5-4 \mathrm{mg}$ in patients taking clonazepam alone 


\author{
CLONAZEPAM \\ $\mathrm{n} \mathrm{mol} / \mathrm{l}$
}

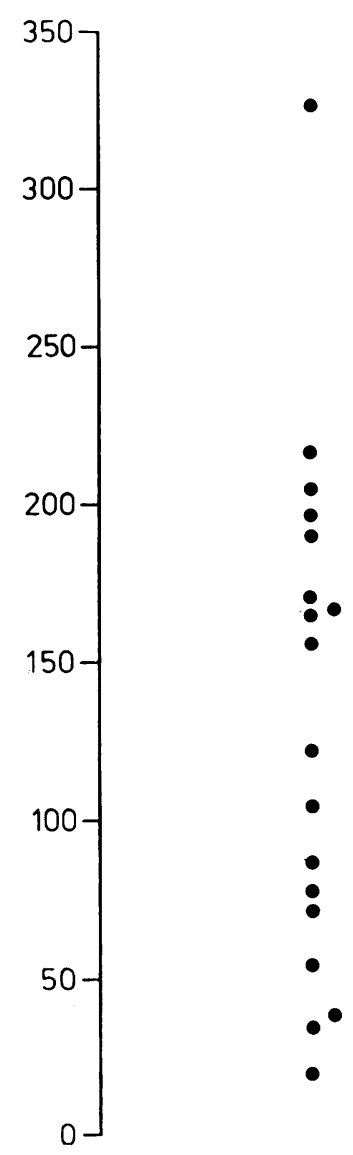

Fig. 3 Plasma clonazepam in well-controlled patients in the open trial on 2-12 $\mathrm{mg}$ of clonazepam daily $(n=18)$.

serum concentrations ranged from $40-240 \mathrm{nmol} / \mathrm{l}$. We found that patients in the double-blind trial who showed clonazepam concentrations below $40 \mathrm{nmol} / 1$ were those who responded poorly to the drug. Our results suggest that treatment with other anticonvulsants, particularly phenobarbitone or primidone (which metabolises to phenobarbitone), lowers serum concentrations of clonazepam. In particular, all of the patients with focal epilepsy treated with phenobarbitone and clonazepam showed high serum concentrations of phenobarbitone and low concentrations of clonazepam in keeping with this suggestion.

Conflicting reports have suggested previously that clonazepam may either raise or depress phenytoin or phenobarbitone serum concentrations (Edwards and Eadie, 1973; Daurella, 1974; Hara et al., 1976), but it

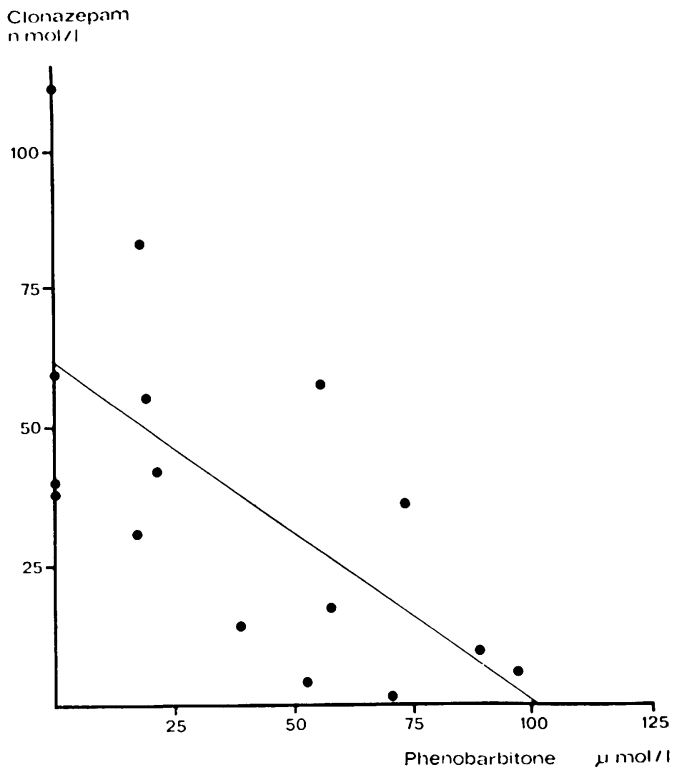

Fig. 4 Relationship between plasma concentrations of clonazepam and phenobarbitone $(n=16) \mathrm{P}<0.01$.

has also been concluded (Huang et al., 1973) that there is no constant effect of clonazepam medication on serum concentrations of other anticonvulsants, and that an increase in phenytoin concentrations might bee due to more constant drug intake because of closer supervision. Our observations indicate that serum concentrations of phenytoin, phenobarbitone, and primidone were not altered by the addition of $3 \mathrm{mg}$ of clonazepam daily. We have found some evidence that the dose of clonazepam has to be increased with time in a few patients on long-term treatment. It remains to be defined whether this is due to tolerance to clonazepam or to accelerated metabolism of the drug.

We conclude that clonazepam is very effective in epilepsy with associated myoclonus and in photosensitive epilepsy. It may also help some patients with temporal lobe epilepsy. It is possible that other anticonvulsants taken in conjunction with clonazepam depress serum clonazepam concentrations, and this may be of importance in therapy.

We thank Roche Products Ltd for support of RNN, Scottish Hospital Endowments Research Trust for support of HJK, and the Secretary of State for Scotland for support of DGL. We also thank Dr G. D. Morrice for help with the patients studied at the Epilepsy Centre, Quarrier's Homes, Bridge of Weir. 


\section{References}

Browne, T. R., and Penry, J. K. (1973). Benzodiazepines in the treatment of epilepsy. Epilepsia (Amsterdam), 14, 277-310.

Daurella, O. L. (1974). Importance of the absorption, biotransformation and elimination of antiepileptic drugs in the treatment of the epileptic. Medicina Clinica, 62, 370-376.

Dreifuss, F. E., Penry, J. K., Rose, S. W., Kupferberg, H. J., and Sato, S. (1975). Serum clonazepam concentrations in children with absence seizures. Neurology (Minneapolis), 25, 255-258.

Edwards, V. E., and Eadie, M. J. (1973). Clonazepam-a clinical study of its effectiveness as an anticonvulsant. Proceedings of the Australian Association of Neurologists, 10, 61-66.

Goldberg, M. A., and Dorman, J. D. (1976). Intention myoclonus: successful treatment with clonazepam. Neurology (Minneapolis), 26, 24-26.

Goudie, J. H., and Burnett, D. (1973). A gas-chromatographic method for the simultaneous determination of phenobarbitone, primidone and phenytoin in serum using a nitrogen detector. Clinica Chimica Acta, 43, 423-429.

Hara, T., Inami, M., and Kaneko, T. (1976). The effects of clonazepam on plasma diphenylhydantoin level in epileptic patients. In Epileptology. Edited by D. Janz. Proceedings of 7 th International Symposium on Epilepsy, Berlin, 1975, p. 152.
Huang, C. Y., McLeod, J. G., Sampson, D., and Hensley, W. J. (1973). Clonazepam in the treatment of epilepsy. Proceedings of the Australian Association of Neurologists, 10, 67-74.

Huang, C. Y., McLeod, J. G., Sampson, D., and Hensley, W. J. (1974). Clonazepam in the treatment of epilepsy. Medical Journal of Australia, 2, 5-8.

Lund, M. (Editor) (1972). Symposium on the therapeutic use of the anticonvulsant Ro5-4024 (clonazepam) in different forms of epilepsy. Acta Neurologica Scandinavica, Supplement 53, 49, 1-143.

Naestoft, J., Lund, M., Larsen, E., and Hvidberg, E. (1973). Assay and pharmacokinetics of clonazepam in humans. Acta Neurologica Scandinavica, Supplement 53, 49, 103-108.

Nanda, R., Keogh, H. J., Lambie, D., Johnson, R. H., Melville, I. D., and Morrice, G. D. (1976). The effects of clonazepam upon epilepsy control and plasma levels of other anticonvulsants. In Epileptology. Edited by D. Janz. Proceedings of 7 th International Symposium on Epilepsy, Berlin, 1975, pp. 145-151.

Scollo-Lavizzari, G., Pralle, W., and de la Cruz, N. (1974). Clinical experience with clonazepam (Rivotril) in the treatment of epilepsy in adults. European Neurology, 11, 340-344.

Van Woert, M. H., and Sethy, V. H. (1975). Therapy of intention myoclonus with L-5-hydroxytryptophan and a peripheral decarboxylase inhibitor Mk 486. Neurology (Minneapolis), 25, 135-140. 